\title{
Quality by Design in Education (QbDE)-A Possible Futuristic Approach to Improve Current Status of Pharmaceutical Education in India
}

\author{
Saranjit Singh \\ National Institute of Pharmaceutical Education and Research (NIPER), Sector 67, SAS Nagar-160062 Punjab, India.
}

\begin{abstract}
Pharmacy education in India needs a drastic change. In the last decade, there has been uncontrolled spurt in number of pharmacy colleges. But only few of them have infrastructure and experienced faculty members to train and teach the students to become a quality professional. The situation is such that most college managements resort to one or other type of malpractice to seek regulatory approvals and to attract students to their institutions. This must stop and both regulatory bodies and managements need to seriously ponder over the same. In the opinion of the author, extension of quality-by-design $(\mathrm{ObD})$ concept to pharmaceutical education is the one possible way out. $\mathrm{QbD}$ is primarily meant for implementation in pharmaceutical industry, where it aims is to build quality into the finished product, without reliance on end testing. Similarly, $\mathrm{QbD}$ in education (QbDE) would mean building quality in students through effectively designed policies, curriculum and teaching/training program incorporating continuous evaluation, so that every student has equal quality and employability. Implementation of QbDE, both at macro and micro levels, is expected to help pharmacy students to adapt to the reality of the $21 \mathrm{st}$ century and enter active life, the world of work, and society, which is becoming extremely competitive day-by-day. At macro level, QbDE would require establishing policies, procedures and controls that aim at all institutions having similar high quality infrastructure, facilities and faculties so as to produce highly trained students. At the micro level, QbDE tends to focus upon a teaching and training program that aims at all students in a class having similar knowledge and skill set and hence employability, despite that students may be from different backgrounds, levels of intelligence, and capacity to learn. It is the conviction of the author that if ObDE concept is taken seriously, the situation can be significantly improved from the distasteful condition we are in today.
\end{abstract}

Key words: Pharmaceutical education, Explosion, Outcomes, Quality-by-design, Implementation.

\section{INTRODUCTION}

An explosion of pharmacy education has happened in the last few decades. There has been spurt in number of institutions, number of students, and types of degrees and streams. The outcome of this growth has been both positive and negative. While the students have an easy choice to pursue pharmacy as a career, against the situation where only few privileged could get admission earlier, the uncontrolled growth in number of pharmacy institutions and ever enhancing number of sanctioned seats has unsettled the situation. The absence of quality teachers and training/research facilities in majority of institutions has lead to decline in the worth of the students, who have been reduced to status of a cheap labor. Other ills have also crept in pharmaceutical education, like offer of money by institutions to students for taking admission, award of degrees to nonattending students, non-payment of due salary to teachers, forcing teachers to pass the students, tendency of inspectors of statutory bodies to accept or seek financial alms from institutional managements, etc. The situation needs to be changed urgently, for which a systematic thought process and effort is needed. One possible way is to extend the Quality by Design concept, which recently has been implemented in pharmaceutical
Submission Date : 18-06-2015 Revision Date : :24-08-2015 Accepted Date : :01-09-2015

DOI: 10.5530/ijper.50.1.6 Correspondence Address Dr Saranjit Singh

National Institute of Pharmaceutical Education and Research, Sector67, SAS Nagar 160062, Punjab, India.

Email:ssingh@niper.ac.in

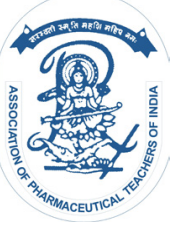

www.ijper.org 


\begin{tabular}{|c|c|c|c|}
\hline Period & \multicolumn{2}{|c|}{ Number of Institutions } & Number of Students \\
\hline $1980 s$ & \multicolumn{2}{|c|}{37} & 2000 (UG+PG) \\
\hline Today & $\begin{array}{l}\text { PCI Approved: } \\
\text { AICTE Approved: }\end{array}$ & $\begin{array}{l}30 \\
717 \text { D. Pharm., } \\
968 \text { B. Pharm., } \\
160 \text { Pharm. D. } \\
\text { (incl. PB) } \\
498 \text { D. Pharm., } \\
1029 \text { B.Pharm. } \\
841 \text { M.Pharm. }\end{array}$ & $\begin{array}{c}\sim 1,50,000 \\
\text { (Diploma+UG+PG) }\end{array}$ \\
\hline
\end{tabular}

processing and manufacturing, to pharmaceutical education.

\section{THE CURRENT STATUS OF PHARMACEUTICAL EDUCATION IN INDIA AS COMPARED TO 1980}

The pharmacy education in India, which started with inception of the first course in 1937 at Banaras Hindu University at Varanasi, grew at a very slow pace till 1963, with only 10 institutions offering pharmacy courses. ${ }^{1}$ Of these, only Lallubhai Motilal College of Pharmacy, Ahmedabad and Birla Institute of Technology and Science, Pilani were in the private sector. The number grew slowly to 37 in 1980s with 11 Universities and 26 Colleges offering the courses. ${ }^{2}$ Within last three decades, and particularly in the last decade, the number of institutions have grown at a very fast pace, with PCI and AICTE approved institutions around 1900 today (Table 1). Majority of these are in the private sector. With growth in the number of institutions, there has been a parallel increase in intake of students also. The number has gone from $\sim 2000$ in 1980s to as high as $\sim 1.5$ lacs today (Table 1). ${ }^{3,4}$ The degrees awarded have also grown in numbers, as outlined in Table 2 . The same is the case with streams at the Master's level, where the number has grown up from conventional four streams, by multiple times, as depicted in Table 3. Table 4 provides the comparison of orientation of pharmacy education in 1980s and today. Evidently, not much change has happened on this aspect, with major emphasis still on preparing students for employment in industry. Effort has been made to orient education towards community and clinical pharmacy through initiation of Pharm. D. program, but the latter has yet to show the real impact, as students have just started leaving the campuses upon completion of their education.

With the major spurt happening in short duration of the last decade, majority of institutions/colleges could not hire quality teachers, as their number did not increase
Table 2: Multitude of degrees offered today in comparison to standard four in 1980 s

\begin{tabular}{|c|c|}
\hline Period & Degrees \\
\hline \multirow{4}{*}{ 1980s } & D. Pharmacy \\
\hline & B. Pharmacy \\
\hline & M. Pharmacy \\
\hline & Ph.D. \\
\hline \multirow{12}{*}{ Today } & D. Pharmacy \\
\hline & B. Pharmacy \\
\hline & Pharm. D. \\
\hline & M. Pharmacy \\
\hline & M.S. (Pharm.) \\
\hline & M.Sc. (Applied) \\
\hline & M.Tech. (Pharm.) \\
\hline & $\begin{array}{l}\text { B.Pharm. + M.B.A. (Pharm. Tech.) 5-year } \\
\text { Integrated }\end{array}$ \\
\hline & M.B.A. (Pharma Management) \\
\hline & M.Pharm. + M.B.A. 3-year Integrated \\
\hline & Post-Graduate Diplomas \\
\hline & Ph.D. \\
\hline
\end{tabular}

in parallel. Table 5 shows the comparative situation in 1980s and today. Earlier generations of students, including the author, were taught by legendry professors, who all were doctorates with rich teaching and research experience. Today, a B. Pharm. teaches undergraduates, and fresh M. Pharm. pass outs are assigned to teach and train post-graduate and graduate students. It was saddening to read the news under the title 'Students ask PCI to initiate immediate action against erring pharma colleges for fake faculty', which appeared on the e-portal pharmabiz.com on 24 January 2012. ${ }^{5}$ This situation of 'fake faculty' can be least expected, with pharmacy education being under the umbrella of two statutory bodies.

Hence there is no doubt that higher education is thoroughly commercialized today and is in the hands of market forces. The private sector, which accounted for about $10 \%$ of the students admitted in the 1980 s, now accounts for $91 \%$ of all students admitted. ${ }^{6}$ The major- 


\begin{tabular}{|c|c|}
\hline $1980 \mathrm{~s}$ & Today \\
\hline Pharmaceutical Chemistry & Pharmaceutical Chemistry, Medicinal Chemistry, Process Chemistry, Bulk Drug Technology \\
\hline Pharmaceutics & Pharmaceutics, Pharmaceutical Technology, Industrial Pharmacy \\
\hline Pharmacology & Pharmacology, Pharmacology and Toxicology, Regulatory Toxicology \\
\hline \multirow[t]{10}{*}{ Pharmacognosy } & $\begin{array}{c}\text { Pharmacognosy, Pharmacognosy and Phytochemistry, Phytopharmacy and Phytomedicine, Natural } \\
\text { Products, Traditional Medicines, Herbal Drug Technology }\end{array}$ \\
\hline & $\begin{array}{c}\text { Pharmacy Practice, Clinical Pharmacy, Hospital Pharmacy, Drug Discovery, Drug Discovery and Drug } \\
\text { Development, Clinical Research }\end{array}$ \\
\hline & $\begin{array}{c}\text { Quality Assurance, Pharmaceutical Analysis, Pharmaceutical Analysis and Quality Assurance, Quality } \\
\text { Analysis }\end{array}$ \\
\hline & Biotechnology, Pharmaceutical Biotechnology \\
\hline & Bioinformatics, Pharmacoinformatics \\
\hline & Drug Regulatory Affairs \\
\hline & Pharmaceutical Administration \\
\hline & Pharmaceutical Sciences \\
\hline & Quality Improvement Program \\
\hline & $\begin{array}{l}\text { M.B.A.(Pharm. Tech.) 5-year Integrated; M.B.A.(Pharma Management), M.B.A. (Pharma); } \\
\text { Pharmaceutical Marketing Management }\end{array}$ \\
\hline
\end{tabular}

\begin{tabular}{|c|c|}
\hline \multicolumn{2}{|c|}{ Table 4: Comparison of orientation of pharmacy education in 1980s and today } \\
\hline 1980s & Today \\
\hline $\begin{array}{c}\text { Graduates were mainly trained to work in the pharmaceutical } \\
\text { industry as product and formulation scientists. }\end{array}$ & $\begin{array}{c}\text { Not much change, except new areas of training for increased } \\
\text { vistas in Industry, like Quality Assurance and Regulatory } \\
\text { Affairs. }\end{array}$ \\
\hline $\begin{array}{c}\text { Clinical or pharmacotherapeutic courses received little } \\
\text { coverage in the curriculum and no graduate ever underwent } \\
\text { pharmacy practice experiences. }\end{array}$ & $\begin{array}{c}\text { A few institutions have initiated dedicated clinical or } \\
\text { pharmacotherapeutic courses. Pharm. D. program has been } \\
\text { initiated specifically for the purpose. }\end{array}$ \\
\hline
\end{tabular}

\begin{tabular}{|c|c|}
\hline \multicolumn{2}{|c|}{ Table 5: Quality of teachers in 1980s and today } \\
\hline 1980s & Today (in many institutions) \\
\hline $\begin{array}{c}\text { Required number of teachers, all Ph.Ds., many } \\
\text { leg }\end{array}$ & A fresh M. Pharm. \\
\hline $\begin{array}{c}\text { Taught B. Pharm., M. Pharm. and } \\
\text { guided Ph.D. research }\end{array}$ & $\begin{array}{c}\text { Teaches B. Pharm. and even M. Pharm. } \\
\text { (even B. Pharm. teaches undergraduates) }\end{array}$ \\
\hline
\end{tabular}

ity of institutions in private sector, especially that are working on 'education as a profitable business' principle, have come out with grand and spacious buildings to attract the students, but inside one finds minimal training facilities and near absence of equipment/instruments, required in today's time for student training and research at either graduate, post-graduate and doctorate level. And the irony is that these institutions have sanctioned seats in triple digits.

Practically, there is glut today, with the situation getting so low that there are more number of colleges and less number of students available. This trend is now at a national level, with seats going vacant in institutions in all the states. News items/comments like 'Pharmacy first round: Students apply, then fail to turn up" and "Is pharmacy education on the brink of a shutdown?? are regular in the press. Clearly, we are in the midst of the problem of plenty. The author is of the conviction that 'survival of the fittest' rule is likely to lead to closure of the colleges that are unable to maintain minimum standards of education. Like, many private institutes have already shut down in Andhra Pradesh. ${ }^{9}$ But still the number of institutions and number of students tend to be much more than actually required for quality education and to fill the available employment opportunities. The sad situation is that a pharmacy student, whether 
a graduate or a post-graduate, has been rendered as a cheap labor. This situation may be beneficial to certain category of employers, but poor quality student output is a deep worry for pharmaceutical industry at large, which is presently under extreme pressure due to everincreasing regulatory scrutiny and competition. Good pharmaceutical companies today are avoiding unskilled pharmacy graduates and post-graduates, and have started preferring students from sciences, which is again unfortunate.

Thus pharmacy education urgently requires saving from this quagmire situation, the pain of which is being felt all around. Everybody wishes for a quick turnaround, through a solution that is dependable in the long-term.

\section{QbD IN EDUCATION (QbDE) AS A FUTURE APPROACH TO IMPROVE THE SITUATION}

The author feels that to amend the situation, time has come now for the academic institutes to carry out self introspection to ensure their own subsistence. They need to adopt a new quality policy: 'Excellent buildings, excellent teaching and training infrastructure, and best faculty-we commit to bring out highest quality students.' However, a more systematic effort is needed to bring the desired and a lasting change. According to the author, the extension of Quality-by-Design (QbD) to pharmacy education can be considered as one sound approach to improve the situation in the long-term. $\mathrm{QbD}$ is a very fresh concept, which recently has been sought to be implemented in pharmaceutical development and production by International regulatory agencies. ${ }^{10}$ It is rather a revolutionary change in assurance of product quality. From today's era, where quality is controlled primarily by inspection and finished product testing, QbD aims at building quality into the finished product, with little or no reliance on end testing.

There are four key elements in the implementation of QbD: i) define target product quality profile, ii) design product and manufacturing process, iii) identify critical quality attributes, process parameters and source of variability, and iv) control manufacturing practices to produce consistent quality over time (core of Figure 1). Thus QbD lays down emphasis on gaining complete knowledge about properties of the drug(s), excipients, packaging, interactions between components, process involved in development/manufacturing, etc. This is followed by identification of key parameters that may cause variability and hence influence the final drug/ product quality. For this, use of risk management and design tools are employed. Eventually, on-line analytical instruments are placed to control the critical parameters during processing at the shop floor. In this manner, one can assure that every lot of active pharmaceutical ingredient and every dosage form unit is of optimal quality, thus reducing the requirement of end-product testing. The QbD in Education (QbDE), in the same context, means building quality in students through effectively designed policies, curriculum and teaching/training program incorporating continuous evaluation. This has become truly important as today's students want solid education, where curriculum and teaching methods are up-to-date; they also want teaching and training that helps them adapt to the reality of the $21^{\text {st }}$ century and is useful for entering active life, the world of work, and society, which is becoming extremely competitive day-by-day. It is only through consideration of $\mathrm{QbD}$ elements, both at macro and micro levels, that these ambitions of students can be achieved holistically.

Figure 1 also includes QbDE flow at the macro level. Its implementation requires establishing policies, procedures and controls that aim at all institutions having similar high quality infrastructure, facilities and faculties so as to produce highly trained students having equal employability potential. This is despite that the institutions may be located in any part of the country, managed by different managements, and belong to private or public sector. Though statutory bodies like PCI and AICTE have this mandate, yet there is visible failure all around. For this, the author suggests initiation of discussion among all the stakeholders (Table 6 ) on why the current education level has come down and how best the scenario can be amended. This responsibility shall be taken over by professional organization like APTI, which must work actively to come out with a white paper, listing the gaps and suggesting best possible ways for the improvement.

The author would suggest here the following few points for consideration while preparing such a white paper:

- Evaluation of government policies (centre and states): enlisting flaws and scope of change, if any.

- Statutory control: any suggestions for improvement? Would single agency control be better or dual control shall continue.

- Revision of minimal standards and parameters for evaluation of institutions: Scope for change?

- Enhancement of merit criteria for admissions, like enhancement of cut-off of GPAT exams: Would it help?

- Assessment of expectations and annual job vacancies: In Industry/CROs/CRAMs/ CDSCO/state regulatory/government and private testing laboratories/ hospitals/modern chain of pharmacies/individual retail outlets, etc. 


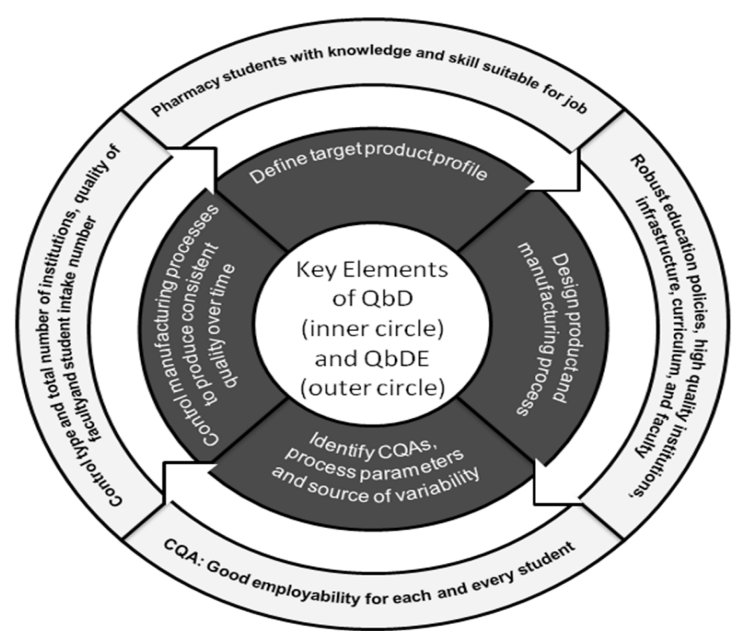

Figure 1: Macro elements of QbDE laid over key components of $\mathrm{QbD}$

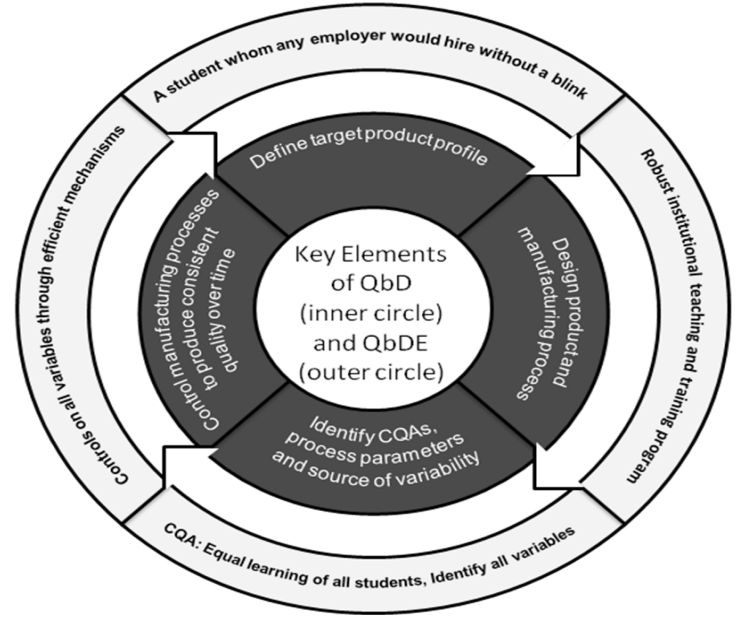

Figure 2: Micro elements of QbDE laid over key components of $\mathrm{QbD}$

\begin{tabular}{|c|c|}
\hline \multicolumn{2}{|c|}{ Table 6: Stakeholders of pharmaceutical education } \\
\hline Stakeholder & Role \\
\hline Central Government & $\begin{array}{c}\text { Policy, Approval for establishment of Central Universities, National } \\
\text { Institutes, etc. }\end{array}$ \\
\hline Statutory Bodies like AICTE, PCl, etc. & $\begin{array}{c}\text { Eduction Regulation } \\
\text { (Institutional Approvals/Course Curriculum Updating, Practioner } \\
\text { Registration, Student Fellowships) }\end{array}$ \\
\hline State Governments & $\begin{array}{c}\text { Policy, Approval for establishment of State Universities, Local } \\
\text { Institutes, etc. }\end{array}$ \\
\hline Organizations like UGC, DST, DBT, CSIR, etc. & Funding of Researc and Fellowships \\
\hline Universities/Institutes/Colleges & Imparting of Education \\
\hline $\begin{array}{c}\text { Industry/CROs/CRAMs/Hospitals/Clinics/ Medicine Outlets/ } \\
\text { CDSCO/ State Drug Control Departments, Government and } \\
\text { Private Laboratories, etc. }\end{array}$ & Facilitators, Watchdogs \\
\hline Professional Bodies like IPA, IDMA, APTI, etc. & Receiver of Education \\
\hline Students & \\
\hline
\end{tabular}

- Decision on number of institutions and intake of students: Linked to annual job opportunities.

- Study of education and research model of leading Indian and International institutions: Which model is best for wider implementation?

- Scope of revising curriculum: Is current curriculum in line with global trends and challenges currently faced by Industry and all other types of employers?

- Faculty training and faculty development programs: Making them more effective through regional training institutes, whether feasible or not?

- Funding of research fellowships and research projects: Shall not it be taken over by Department of Pharmacenticals?

Along with the above, a strong recommendation of the author would be to use optimal statistical and design models to assess the requirement of the number of institutions, infrastructure, faculty, students; right education model (local or International); most suited curriculum; and identification of variables, which may require stringent control. The final recommendations must touch upon the nature of controls that can be implemented by statutory bodies, and also by educational institutions themselves to radically change the current scenario of pharmaceutical education.

At the micro level, QbDE focuses upon a teaching and training program that aims at all students in a class having similar knowledge and skill set and hence employability, despite that students may be from different backgrounds, levels of intelligence, and capacity to learn. This micro model of QbDE is described in Figure 2. It again requires identification of all variables that can influence equal learning of all students in the class, followed by having controls on the critical variables, identified through risk management approach. An added element here is replacement of end-term testing by continuous evaluation system, with end examinations given relatively low weightage. This system has 
advantage in terms of reduction of anxiety and stress of final examinations. As such also, in today's environment of campus placements, the employers hardly pay attention to final marks sheets or the degrees. So these have no relevance left, except acting as a certificate of completion of the degree, just good for placing in personal files.

The expected QbDE elements (and variables) at micro level are:

- Quality policy of the institution

- Learning environment in the institution (management guided discipline)

- Facilities in terms of enough number of class rooms, laboratories, equipment, audio-visual aids, etc. and assessment of their quality

- Number and qualification of faculty, including assessment of their command on the subject, communication skills, practical experience, punctuality, etc.

- Delivery in class, whether bookish or conceptual

- Existence of mechanism of on-job training and encouragement to attend faculty development programs and seminars/workshops/conferences

- Existence of continuous evaluation system through assignments, spot tests, and other means

- Enough equipment for hands-on practical training of each student

- Special sessions for skill development for all, keenly observing weakness of each student, etc, etc.

Here also QbDE anticipates application of design of experiments (incorporating risk management tools) to identify those variables, which require stringent control that can be implemented by educational institutions and faculty members to ensure equal learning of each student in the class. QbDE at micro level thus aims at

a situation where education is no more a burden for the student, rather it can help in making education and learning a fun. It also endeavors at making all students equally suitable for respectable employment.

\section{CONCLUSION}

Let's all, under the umbrella of APTI and its state wings, with support and involvement of PCI and AICTE, plan and act vigorously and scientifically to improve the current dismal scenario of pharmaceutical education. The QbDE model has good scope in this respect, and if we are successful in implementing the same, perhaps we will be first in the world to do so, for which all pride will be ours.

\section{ACKNOWLEDGEMENTS}

The author appreciates President and Secretary, APTI, for inviting him to address the participants of $19^{\text {th }}$ Annual National Convention of Association of Pharmaceutical Teachers of India (APTICON 2014) held at Pune from $28^{\text {th }}-30^{\text {th }}$ November 2014.

\section{CONFLICT OF INTEREST}

The author reports no conflict of interest.

\section{ABBREVIATIONS}

AICTE : All India Council of Technical Education, New Delhi

APTI : Association of Pharmaceutical Teachers of India

PCI : Pharmacy Council of India, New Delhi

QbD : Quality by Design

QbDE : Quality by Design in Education

\section{REFERENCES}

\section{SUMMARY}

- Need of drastic change in condition of pharmaceutical education in India.

- As compared to 1980s, there is uncontrolled spurt in number of pharmacy colleges, with only few institutions having infrastructure and experienced faculty members to train and teach the students.

- The unsettled situation has resulted in malpractices by college managements and also students have been rendered cheap labor.

- A possible way-out is extension of quality-by-design ( $Q b D$ ) concept to pharmaceutical education.

\section{About Author}

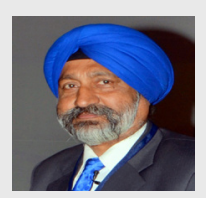

Dr Saranjit Singh: Is Ex-Dean and Professor and Head of the Department of Pharmaceutical Analysis at the National Institute of Pharmaceutical Education and Research (NIPER) at S.A.S. Nagar, Panjab. He is Member, Expert Advisory Panel on the International Pharmacopoeia and Pharmaceutical Preparations, World Health Organization (WHO), Geneva. His research interests include drug stability testing, and drug degradation/metabolite profiling using sophisticated hyphenated techniques like LC-MS and LC-NMR. 
1. S. C. Basak and D.Sathyanarayana, Pharmacy Education in India, Am J Pharm Educ 74(4); May 12, 2010

2. H. Singh, History of Pharmacy in India and Related Aspects. Volume 2: Pharmaceutical Education. 1st ed. Delhi: Vallabh Prakashan; 1994.

3. http://www.aicte-india.org/statistics

4. http://www.pci.nic.in/CollegesCourses/ApprovedDegreeinstitutionsus12.aspx

5. http://pharmabiz.com/NewsDetails.aspx?aid=67165\&sid=1

6. R.Chengappa, Highereducation:Howtocleanthemess. http://http://indiatoday. intoday.in/story/Higher+Education:+How+to+clean+the+mess/1/49794.html
7. http://timesofindia.indiatimes.com/city/ahmedabad/Pharmacy-first-roundStudents-apply-then-fail-to-turn-up/articleshow/39708384.cms

8. http://timesofindia.indiatimes.com/city/ahmedabad/2400-seats-vacant-inpharmacy-colleges/articleshow/15084609.cms

9. http://www.deccanchronicle.com/140721/nation-current-affairs/article/manyprivate-andhra-pradesh-institutes-shut-down

10. http://www.raps.org/focus-online/news/news-article-view/article/4265/ 